\title{
Analisis Performa Eccentrically Braced Frames (EBF) Vertikal Link Menggunakan Wide Flange (WF) Link
}

\author{
Pramesta Armanisag Pangestuti ${ }^{1, *}$, Budi Suswanto ${ }^{1}$ \\ Departemen Teknik Sipil, Institut Teknologi Sepuluh Nopember, Surabaya ${ }^{1}$ \\ Koresponden*, Email: pramestaarma@gmail.com
}

\begin{tabular}{|c|c|c|}
\hline & Info Artikel & Abstract \\
\hline Diajukan & 06 Juli 2021 & Eccentrically Braced Frames (EBF) is an earthquake resistant steel structure that has good \\
\hline Diperbaiki & 19 Juli 2021 & shear capacity and ductility. The EBF structure makes the link the element that is damaged \\
\hline Disetujui & 20 Juli 2021 & $\begin{array}{l}\text { first than the other elements. EBF has } 2 \text { types of links, namely vertical links and horizontal } \\
\text { links. The horizontal link of the EBF rotates in the vertical direction after a large earthquake } \\
\text { occurs so that it interferes with other elements above it and makes it difficult to repair or replace } \\
\text { the link, the solution is to use a vertical link which allows for link repair or replacement, } \\
\text { without changing the beam section. An analysis was carried out in the form of a 10-story } \\
\text { building structure with a vertical link EBF structure system using SAP } 2000 \text { software in the } \\
\text { form of linear and non-linear analysis. Then, a cyclic load analysis was carried out for the } 1- \\
\text { story frame specimen of the vertical link EBF structure system using Abaqus CAE software. }\end{array}$ \\
\hline $\begin{array}{l}\text { Keywords: } \\
\text { vertical lin } \\
\text { and non-lin }\end{array}$ & $\begin{array}{l}\text { trically Braced Frames, } \\
\text { te element method, linear } \\
\text { nalysis, cyclic load }\end{array}$ & $\begin{array}{l}\text { The results of the analysis showed that the modeling of the 10-storey building structure and the } \\
\text { 1-story frame specimen experienced element failure first in the link, this is in accordance with } \\
\text { the concept of Eccentrically Braced Frames }(E B F) \text { structure. }\end{array}$ \\
\hline
\end{tabular}

Abstrak

Eccentrically Braced Frames (EBF) merupakan struktur baja tahan gempa yang memiliki kapasitas geser dan daktilitas yang baik. Struktur EBF menjadikan link sebagai elemen yang mengalami kerusakan terlebih dahulu dari elemen lainnya. EBF mempunyai 2 tipe link, yaitu link vertikal dan link horizontal. Link horizontal EBF berotasi ke arah vertikal pasca terjadi gempa besar sehingga mengganggu elemen lain di atasnya dan sulit melakukan perbaikan atau penggantian link, solusinya digunakan link vertikal yang memungkinkan untuk perbaikan atau penggantian link, tanpa mengubah bagian balok. Dilakukan analisis berupa struktur gedung 10 lantai dengan sistem struktur EBF link vertikal menggunakan software SAP 2000 berupa analisis linier dan non linier. Selanjutnya dilakukan analisis beban siklik untuk spesimen frame 1 lantai sistem struktur EBF link vertikal menggunakan software Abaqus CAE. Hasil analisis menunjukkan bahwa pemodelan struktur gedung EBF 10 lantai dan spesimen frame EBF 1 lantai mengalami kegagalan elemen terlebih dahulu terjadi pada link, hal ini sesuai dengan konsep struktur Eccentrically Braced

Kata kunci: Eccentrically Braced Frames, link vertikal, metode elemen hingga, analisis linier dan non linier, beban siklik $\quad$ Frames (EBF).

\section{Pendahuluan}

Konstruksi struktur baja merupakan salah satu sistem struktur tahan gempa dengan kinerja yang baik, dengan mengandalkan sifat kekuatan dan daktilitas material baja yang tinggi. Struktur baja juga mampu mendisipasi energi yang besar untuk menghindari dan meminimalisir terjadinya keruntuhan. Dengan sifat-sifat material baja yang daktail, kekuatan yang tinggi, dan kemampuan dalam mendisipasi energi yang baik, maka struktur baja sangat cocok apabila digunakan untuk daerah-daerah dengan tingkat seismisitas yang tinggi. Jenis-jenis model sistem struktur baja tahan gempa, antara lain: Momen Resisting Frames (MRF), Concentrically Braced Frames (CBF), Eccentrically Braced Frames (EBF), Buckling Restrained Braced Frames (BRBF), dan Steel Plate Shear Walls (SPSW) [1].
Eccentrically Braced Frames (EBF) merupakan sistem yang membatasi perilaku inelastik hanya terjadi pada balok link yang berada di antara dua pengekang eksentrik, sedangkan balok bagian luar, kolom, dan pengekang diagonal tetap elastik selama beban seismik bekerja [2]. Link didefinisikan sebagai jarak yang dibuat di antara 2 ujung bracing, atau jarak antara bracing dengan kolom, atau jarak antara bracing dengan balok. Panjang link dinotasikan dengan huruf " $e$ ". Fungsi utama dari link adalah sebagai elemen yang didesain mengalami leleh terlebih dahulu dari semua komponen Eccentrically Braced Frames (EBF), yang memiliki kapasitas deformasi plastis dan dapat mendisipasi energi yang dihasilkan oleh gempa bumi, dengan konfigurasi tipe link pada struktur EBF seperti ditunjukkan pada Gambar 1 [3]. 


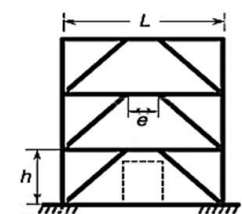

(a)

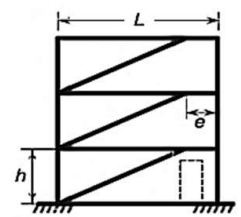

(b)

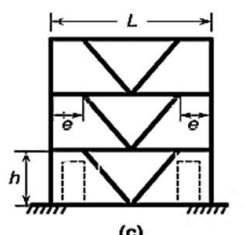

(c)

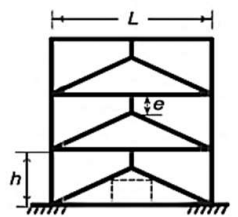

(d)

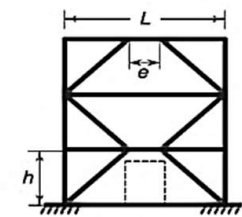

(e)
Gambar 1. Konfigurasi Eccentrically Braced Frames [1]

Eccentrically Braced Frames (EBF) secara umum mempunyai 2 tipe, yaitu EBF dengan horizontal link (H-EBF) dan EBF dengan vertikal link (V-EBF). Eccentrically Braced Frames (EBF) dengan horizontal link (H-EBF), link menjadi satu kesatuan dengan balok sehingga melakukan perbaikan atau penggantian link yang mengalami kerusakan pada $\mathrm{H}-$ EBF pasca terjadinya gempa besar bisa sangat sulit dan mengganggu sistem struktur lain [4]. Berdasarkan kelemahan dari H-EBF tersebut, maka digunakan V-EBF dimana pada V-EBF memungkinkan untuk perbaikan atau penggantian elemen link yang rusak pasca terjadi gempa besar, tanpa mengganti atau mengubah bagian dari balok [5]. V-EBF merupakan sistem Eccentrically Braced Frames dimana link dipasang secara vertikal mengubungkan bracing dengan balok.

Penelitian yang dilakukan oleh Shayanfar dkk. [6] menunjukkan bahwa Eccentrically Braced Frames dengan link vertikal (V-EBF) mempunyai kelebihan dari sistem H-EBF, antara lain pada daktilitas, kekuatan elastis yang tinggi, fungsionalitas sebagai sistem fuse yang daktail, dan keefektifan dalam proses bongkar pasang pasca terjadi kerusakan tanpa mengganggu elemen struktur lainnya. Penggunaan link vertikal, dimensi penampang link dapat didesain dengan fleksibel tanpa harus memiliki dimensi dan profil penampang yang sama dengan balok. Penelitian Eccentrically Braced Frames (EBF) dengan link vertikal juga dilakukan oleh Wang [5] dengan menggunakan High Strength Steel (HSS) dan dilakukan secara eksperimental. Link yang digunakan dalam eksperimental tersebut adalah menggunakan jenis link pendek/link geser. Hasil dari eksperimental disebutkan bahwa berilaku Y-HSS-EBF menunjukkan kinerja yang baik untuk deformasi plastis. Kurva histeresis antara gaya dan displacement menunjukkan perilaku deformasi plastis yang baik dan tidak menghasilkan pinching atau penjepitan pada kurva histeresis.

\section{Metode}

Studi ini akan menganalisis struktur Eccentrically Braced Frames (EBF) dengan menggunakan konsep vertikal link, dimana link dipasang secara vertikal menghubungkan balok dengan bracing eksentris. Dilakukan analisis pada struktur Eccentrically Braced Frames (EBF), yaitu dengan menggunakan link profil Wide Flange (WF) sesuai dengan preliminary design yang dilakukan, dan analisis tidak mendetailkan atau menghitung sistem sambungan. Tujuan dari analisis ini adalah untuk mengetahui perilaku atau performa dari Eccentrically Braced Frames (EBF) link vertikal dengan diharapkan hasil struktur dengan kapasitas geser, disipasi energi, dan daktilitas yang baik.

Analisis dilakukan dengan menggunakan bantuan software SAP 2000 dan Abaqus CAE. Software SAP 2000 digunakan untuk analisis linier dan non linier struktur gedung 3 dimensi 10 lantai Eccentrically Braced Frames (EBF) link vertikal, dengan denah mengacu pada penelitian oleh Suswanto dkk. [7]. Analisis linier pada SAP 2000 mengacu pada persyaratan SNI 1726: 2019 untuk pembebanan gempa dan SNI 1727: 2018 untuk pembebanan struktur gedung yang berupa beban mati tambahan dan beban hidup. Analisis non linier berupa pushover dengan tujuan untuk mengetahui perilaku struktur dan keruntuhan elemen pada struktur. Konsep Eccentrically Braced Frames (EBF) adalah pelelehan atau plastifikasi terlebih dahulu terjadi pada elemen link, sedangkan elemen lain masih dalam kondisi elastis. Analisis selanjutnya adalah analisis berupa pemberian beban siklik pada Abaqus CAE. Analisis ini menggunakan pemodelan frame 1 lantai yang mengalami kegagalan dari hasil analisis pada SAP 2000, dan spesimen dinotasikan dengan V-EBF-WF. Beban siklik atau loading protocol yang digunakan untuk analisis pada Abaqus CAE adalah mengacu pada AISC 34116.

Struktur Eccentrically Braced Frames (EBF) yang dianalisis pada SAP 2000 menggunakan kolom King Cross (KC) dengan bentang 8 meter dan tinggi 4 meter untuk masing-masing lantai, sedangkan elemen balok, bracing, dan link menggunakan profil Wide Flange (WF) dengan tipe link vertikal. Klasifikasi tipe link dan jenis pelelehan link yang terjadi dapat dilihat pada Tabel 1, untuk detail pendefinsian material yang digunakan pada analisis pemodelan dapat dilihat pada Tabel 2, serta diagram tegangan-regangan untuk masing-masing material yang digunakan dapat dilihat pada Gambar 2 dan Gambar 3. Jenis link yang digunakan adalah link pendek atau shear link, dimana link tersebut memiliki kegagalan dominan geser sehingga perencanaan panjang link disesuaikan dengan persyaratan link pendek. 
Tabel 1. Klasifikasi Tipe Link berdasarkan AISC 341-16 [8]

\begin{tabular}{clcc}
\hline No. & Nama Link & Panjang Link & Jenis Pelelehan \\
\hline 1 & Link pendek & $e<1,6 M_{p} / V_{p}$ & dominan geser \\
2 & Link menengah & $1,6 M_{p} / V_{p}<e<2,6 M_{p} / V_{p}$ & kombinasi geser dan lentur \\
3 & Link Panjang & $2,6 M_{p} / V_{p}<e$ & dominan lentur \\
\hline
\end{tabular}

Tabel 2. Pendefinisian Material

\begin{tabular}{|c|c|c|c|}
\hline \multicolumn{2}{|l|}{ BAJA } & \multicolumn{2}{|c|}{ BAJA LINK } \\
\hline$f_{y}(\mathrm{MPa})$ & 345 & $f_{y}(\mathrm{MPa})$ & 292 \\
\hline$f_{u}(\mathrm{MPa})$ & 450 & $f_{u}(\mathrm{MPa})$ & 456 \\
\hline Berat Jenis $\left(\mathrm{kg} / \mathrm{m}^{3}\right)$ & 7.850 & Berat Jenis $\left(\mathrm{kg} / \mathrm{m}^{3}\right)$ & 7.850 \\
\hline Young's Modulus E (MPa) & 200.000 & Young's Modulus E (MPa) & 200.000 \\
\hline Poisson's Ratio v & 0,3 & Poisson's Ratio & 0,3 \\
\hline$\varepsilon \max$ & $18 \%$ & $\varepsilon \max$ & $16 \%$ \\
\hline
\end{tabular}

Grafik Tegangan-Regangan pada Material Baja A992

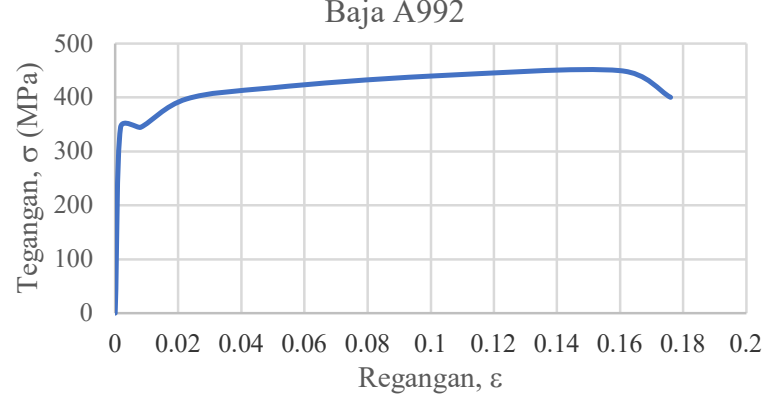

Gambar 2. Kurva Tegangan-Regangan Material Baja A992 [7]

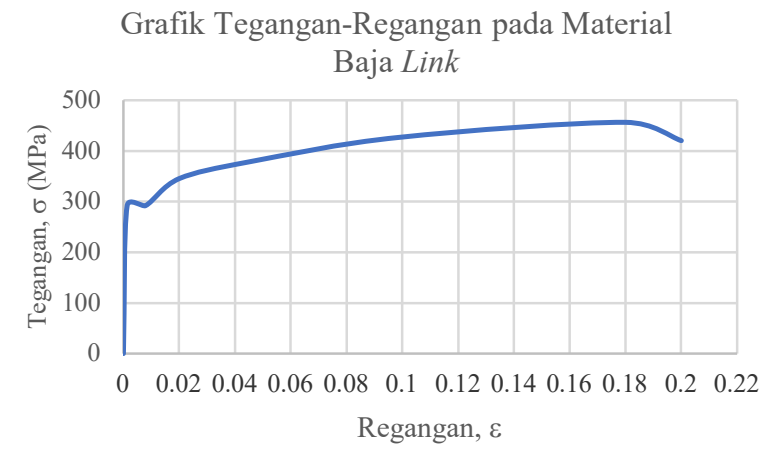

Gambar 3. Kurva Tegangan Regangan Material Baja Link A36 [7]

Tabel 3. Dimensi Rencana Profil Masing-Masing Elemen

\begin{tabular}{|c|c|c|c|c|}
\hline Lantai & Kolom & Balok & Link & Bracing \\
\hline $1-4$ & KC 800x300x14x26 & WF $600 \times 200 \times 11 \times 17$ & 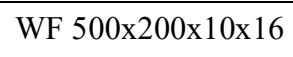 & WF $600 \times 200 \times 11 \times 17$ \\
\hline $5-7$ & $\mathrm{KC} 700 \times 300 \times 13 \times 24$ & WF $600 \times 200 \times 11 \times 17$ & WF $450 \times 200 \times 9 \times 14$ & WF $500 \times 200 \times 10 \times 16$ \\
\hline $8-10$ & KC $588 \times 300 \times 12 \times 20$ & WF $500 \times 200 \times 10 \times 16$ & WF $400 \times 200 \times 8 \times 13$ & WF 450x200x9x14 \\
\hline
\end{tabular}

Tabel 3 merupakan preliminary design dimensi masingmasing elemen yang digunakan dalam analisis menggunakan SAP 2000. Gambar 4 dan Gambar 5 merupakan pemodelan struktur gedung 10 lantai dengan sistem Eccentrically Braced Frames (EBF) link vertikal yang mengacu pada penelitian Suswanto dkk. [7]. Jenis material yang digunakan untuk pemodelan pada SAP 2000 ditunjukkan pada Tabel 2. Pemodelan V-EBF 10 lantai kemudian diberi pembebanan sesuai dengan SNI 1726:2019 dan SNI 1727:2018. Hasil analisis dikontrol terhadap syarat partisipasi massa, periode, gaya gempa dasar, simpangan antar lantai, steel check design, serta dilakukan analisis non linier pushover untuk mengetahui pola kegagalan pada struktur Eccentrically Braced Frames (EBF). Kemudian diambil 1 frame yang mengalami kegagalan dari hasil analisis untuk dilanjutkan analisis beban siklik pada software Abaqus CAE. 


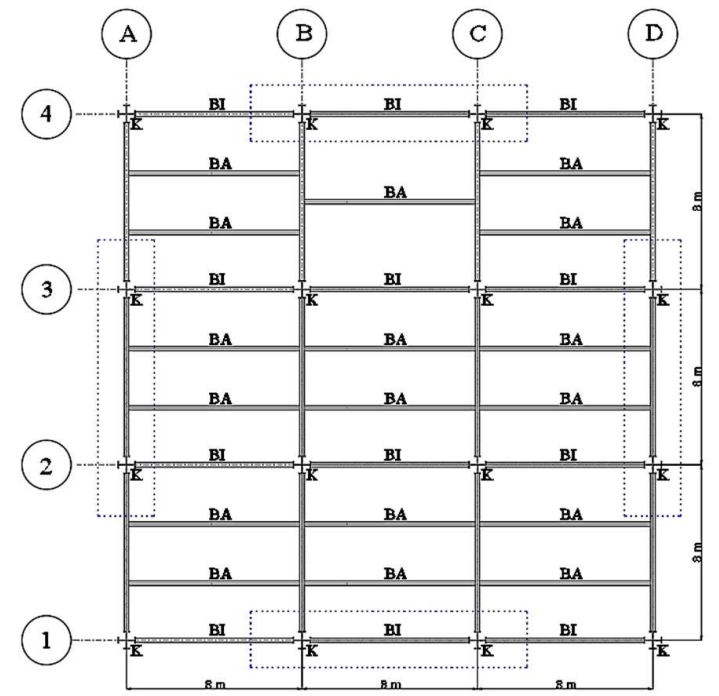

Gambar 4. Denah struktur pemodelan pada SAP 2000 [7]

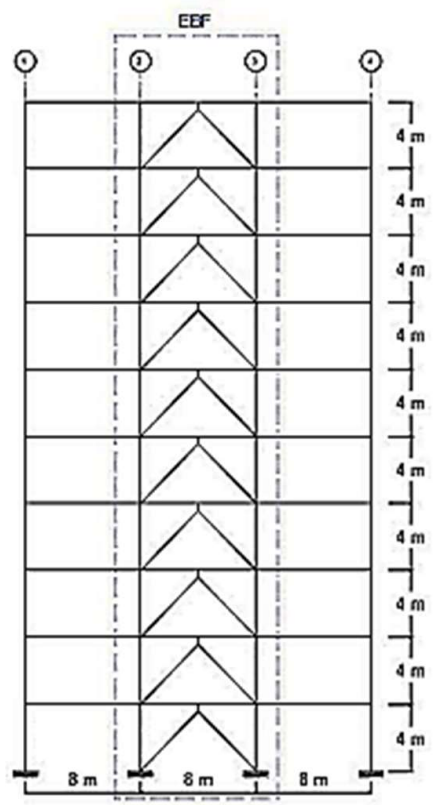

Gambar 5. Pemodelan portal gedung 10 lantai dengan sistem V-EBF [7]

Pemodelan spesimen frame V-EBF-WF pada Abaqus CAE dimulai dari tahapan pemodelan geometri (Modul Part). Tahap ini merupakan tahapan untuk pembuatan bentuk dari masing-masing elemen pada frame berdasarkan dimensi yang telah ditentukan. Penggambaran part yang berupa elemen solid 3 dimensi pada Abaqus CAE dapat dilakukan dengan langsung menggambar masing-masing koordinat dari penampang atau dapat dilakukan dengan import gambar dari software AutoCad, kemudian menyatukan part-part yang telah dibuat dalam bentuk frame dengan modul Assembly. Kemudian dilanjutkan dengan menginput material property seperti tercantum pada Tabel 3 Part yang telah diassembly kemudian dilakukan pemasangan interaksi surface to surface tipe tie constraint. Tahap selanjutnya adalah peletakan Boundary Condition (BC) untuk mendefinisikan letak tumpuan dan letak pemberian beban siklik. Tumpuan frame berada pada ujung bawah kolom atau kaki kolom dan diberikan jenis tumpuan fixed atau jepit. Ujung atas kolom diberi peletakan Boundary Condition (BC) untuk pemberian beban siklik.

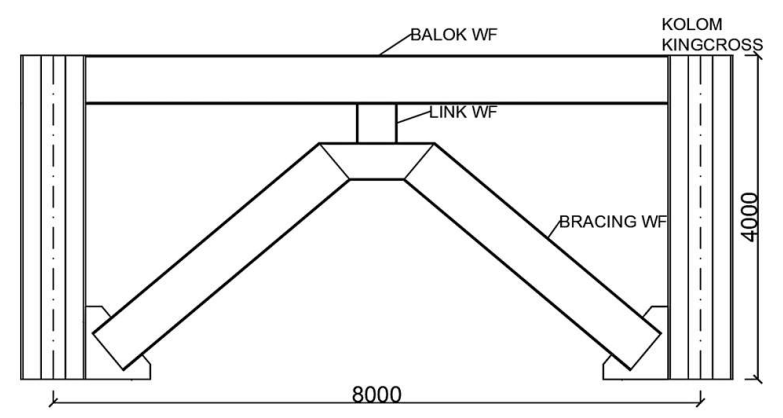

Gambar 6. Pemodelan V-EBF-WF

Loading protocol yang diberikan ketika analisis pada Abaqus CAE mengacu pada AISC 341-16. Pembebanan diberikan secara bertahap dan diawali dengan beban dorong sebesar 0,00375 rad. Total beban siklik yang diberikan selama analisis adalah sebanyak 32 siklus, yang terdiri dari 32 dorongan dan 32 tarikan. Detail rincian nilai loading protocol dapat dilihat pada Gambar 7 dan Tabel 4. Tahap selanjutnya dalam proses pemodelan frame adalah meshing. Meshing merupakan proses pembagian elemen part menjadi elemenelemen kecil untuk pendetailan atau keakuratan dalam hasil analisis. Tipe elemen yang digunakan adalah C3D8R untuk balok, kolom, dan bracing, serta tipe elemen C3D6 untuk link.

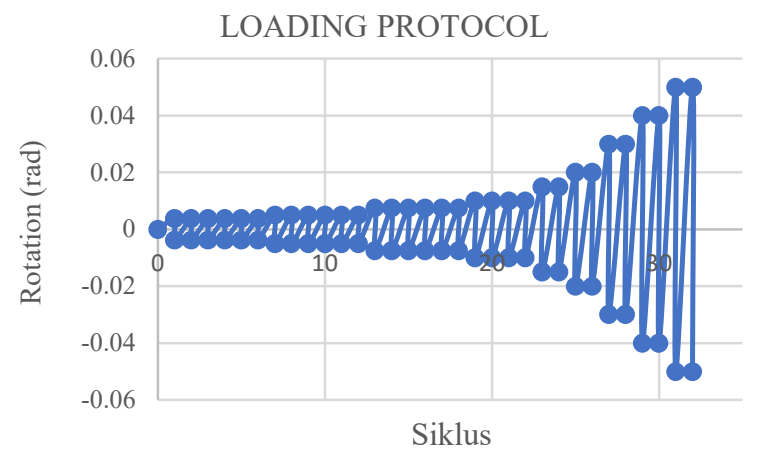

Gambar 7. Loading protocol berdasarkan AISC 341-16 [8]

Evaluasi hasil analisis pemodelan V-EBF-WF yang akan ditinjau adalah kapasitas geser frame, kurva histeresis, 
disipasi energi, pola kegagalan link, dan daktilitas struktur. Selanjutnya dibandingkan performa dari masing-masing spesimen frame V-EBF sehingga didapatkan hasil frame dengan tipe link yang direkomendasikan berdasarkan parameter evaluasi.

Tabel 4. Loading protocol yang digunakan analisis frame V-EBF [8]

\begin{tabular}{cccc}
\hline No. & $\begin{array}{c}\text { Rotation } \\
(\mathrm{rad})\end{array}$ & $\begin{array}{c}\text { Displacement } \\
(\mathrm{mm})\end{array}$ & $\begin{array}{c}\text { Cyclic } \\
\text { Number }\end{array}$ \\
\hline 1 & 0.00375 & 15 & 6 \\
2 & 0.005 & 20 & 6 \\
3 & 0.0075 & 30 & 6 \\
4 & 0.01 & 40 & 4 \\
5 & 0.015 & 60 & 2 \\
6 & 0.02 & 80 & 2 \\
7 & 0.03 & 120 & 2 \\
8 & 0.04 & 160 & 2 \\
9 & 0.05 & 200 & 2 \\
\hline
\end{tabular}

\section{Hasil dan Pembahasan}

\section{A. Analisis Pemodelan pada SAP 2000}

\section{1) Perencanaan Panjang Link}

Berikut merupakan perhitungan panjang link (e) yang digunakan pada pemodelan:

$$
\begin{array}{ll}
f_{y} & =292 \mathrm{MPa} \\
d & =500 \mathrm{~mm} \\
b & =200 \mathrm{~mm} \\
t_{w} & =10 \mathrm{~mm} \\
t_{f} & =16 \mathrm{~mm} \\
M_{p} & =Z_{\mathrm{x}} \times f_{y}
\end{array}
$$$$
\text { dimana: }
$$$$
Z_{x} \quad=\left(b . t_{f}\right)\left(h-t_{f}\right)+t_{w}\left(\frac{1}{2} h-t_{f}\right)\left(\frac{1}{2} h-t_{f}\right)
$$$$
=(200 \times 16)(500-16)+10\left(\frac{1}{2} \times 500-\right.
$$$$
\text { 16) }\left(\frac{1}{2} \times 500-16\right)
$$$$
=2096360 \mathrm{~mm}^{3}
$$$$
M_{p} \quad=\mathrm{Z}_{\mathrm{x}} \times f_{\mathrm{y}}
$$$$
=2096360 \mathrm{~mm}^{3} \times 292 \mathrm{~N} / \mathrm{mm}^{2}
$$$$
=612137120 \mathrm{Nmm}
$$$$
V_{p} \quad=0,6 \times f_{y} \times\left(d-2 t_{f}\right) \times t_{w}
$$$$
=0,6 \times 292 \times(500-2 \times 16) \times 10
$$$$
=819936 \mathrm{~N}
$$$$
\text { e } \quad=1,6 \times \frac{M_{p}}{V_{p}}
$$$$
=1,6 \times \frac{612137120}{819936}
$$

$$
=746,57 \mathrm{~mm}
$$

Maka digunakan panjang link (e) sebesar $400 \mathrm{~mm}<746,57$ mm.

\section{2) Pembebanan Struktur}

Pembebanan struktur yang berupa beban mati tambahan dan beban hidup berdasarkan fungsi gedung perkantoran yang mengacu pada SNI 1727:2018 ditunjukkan pada Tabel 5. Pembebanan Gempa yang digunakan mengambil dari wilayah Surabaya, dengan fungsi gedung sebagai gedung perkantoran, didetailkan pada Tabel 6.

Tabel 5 Pembebanan struktur [9]

\begin{tabular}{llc}
\hline & Beban & \multicolumn{1}{c}{ Nilai } \\
\hline \multirow{2}{*}{ Atap } & Superdead & $0,39 \mathrm{kN} / \mathrm{m}^{2}$ \\
& Live & $0,96 \mathrm{kN} / \mathrm{m}^{2}$ \\
\multirow{2}{*}{ Lantai } & Superdead & $1,44 \mathrm{kN} / \mathrm{m}^{2}$ \\
& Live & $4,79 \mathrm{kN} / \mathrm{m}^{2}$ \\
\hline
\end{tabular}

Tabel 6 Pembebanan gempa [10]

\begin{tabular}{ll}
\hline Parameter & Nilai \\
\hline Wilayah & Surabaya \\
$S_{S}$ & $0,704649 \mathrm{~g}$ \\
$S_{l}$ & $0,304513 \mathrm{f}$ \\
Kategori resiko & II \\
$I_{e}$ & 1 \\
Kelas situs & SE \\
$F_{a}$ & 1,372561 \\
$F_{v}$ & 2,781947 \\
$S_{M S}$ & $0,967174 \mathrm{~g}$ \\
$S_{M I}$ & $0,84714 \mathrm{~g}$ \\
$S_{D S}$ & $0,644783 \mathrm{~g}$ \\
$S_{D 1}$ & $0,56476 \mathrm{~g}$ \\
$T_{0}$ & $0,175178 \mathrm{~s}$ \\
$T_{S}$ & $0,875891 \mathrm{~s}$ \\
Sistem rangka & EBF \\
$R$ & 8 \\
$C_{d}$ & 4 \\
\hline
\end{tabular}

3) Kontrol Partisipasi Massa

SNI 1726:2019 Pasal 7.9.1.1 menjelaskan analisis diizinkan untuk memasukkan jumlah ragam yang minimum untuk mencapai massa ragam terkombinasi paling sedikit 90 $\%$ dari massa aktual dalam masing-masing arah dari respons yang ditinjau.

Tabel 7 merupakan nilai rasio partisipasi massa hasil analisis struktur V-EBF 10 lantai pada software SAP 2000. Hasil analisis menunjukkan bahwa struktur V-EBF telah memenuhi syarat kontrol pasrtisipasi massa dari SNI 
1726:2019 dengan rasio 90\% pada masing-masing arah $\mathrm{x}$ dan y.

Tabel 7 Rasio partisipasi massa struktur V-EBF

\begin{tabular}{llllll}
\hline \multicolumn{5}{c}{ Table: Modal Participating Mass Ratios } \\
\hline Output & Step & Step & \multirow{2}{*}{ Period } & Sum & Sum \\
Case & Type & Num & & UX & UY \\
\hline MODAL & Mode & 1 & 1,291336 & 0,7539 & $4 \mathrm{E}-19$ \\
MODAL & Mode & 2 & 1,280692 & 0,7539 & 0,751 \\
MODAL & Mode & 3 & 0,826073 & 0,7541 & 0,751 \\
MODAL & Mode & 4 & 0,430031 & 0,8976 & 0,751 \\
MODAL & Mode & 5 & 0,424604 & 0,8976 & 0,897 \\
MODAL & Mode & 6 & 0,305123 & 0,8976 & 0,897 \\
MODAL & Mode & 7 & 0,304966 & 0,8976 & 0,897 \\
MODAL & Mode & 8 & 0,304898 & 0,8976 & 0,897 \\
MODAL & Mode & 9 & 0,30484 & 0,8976 & 0,897 \\
MODAL & Mode & 10 & 0,303243 & 0,8976 & 0,897 \\
MODAL & Mode & 11 & 0,303154 & 0,8976 & 0,897 \\
MODAL & Mode & 12 & 0,290297 & 0,8976 & 0,897 \\
MODAL & Mode & 13 & 0,290165 & 0,8976 & 0,897 \\
MODAL & Mode & 14 & 0,290104 & 0,8976 & 0,898 \\
MODAL & Mode & 15 & 0,276138 & 0,8976 & 0,898 \\
MODAL & Mode & 16 & 0,240277 & 0,9407 & 0,898 \\
MODAL & Mode & 17 & 0,235535 & 0,9407 & 0,904 \\
\hline
\end{tabular}

\section{4) Kontrol Periode}

Pemberian batasan nilai waktu getar fundamental (periode) bertujuan untuk mencegah perilaku struktur gedung yang terlalu fleksibel yang mengarah pada kenyamanan pengguna atau penghuni bangunan. SNI 1726:2019 menuliskan batasan nilai waktu getar fundamental (periode) pada pasal 7.8.2.1 dengan rumusan pada persamaan 1 .

$T_{a} \quad=C_{t} . h_{n}^{x}$

Dimana:

$C_{t} \quad=0,0731$ (untuk nilai EBF)

$\mathrm{x} \quad=0,75$ (untuk nilai $\mathrm{EBF}$ )

$h_{n} \quad=40 \mathrm{~m}$

Batas nilai $T_{a}$ :

$\mathrm{T}_{\mathrm{a} \min }=C_{t} \cdot h_{n}^{x}=1,1627 \mathrm{~s}$

$\mathrm{T}_{\mathrm{a} \max }=\mathrm{T}_{\mathrm{a} \min .} C_{u}=1,628 \mathrm{~s}\left(C_{u}\right.$ didapat dari Tabel $17 \mathrm{SNI}$ 1726:2019, bergantung pada nilai $S_{D I}$ )

$\mathrm{T}_{\mathrm{a} \min }<\mathrm{T}$ hasil analisis SAP $2000<\mathrm{T}_{\mathrm{a} \max }$ $1,1627 \mathrm{~s}<1,291 \mathrm{~s}<1,628 \mathrm{~s}$

Maka struktur V-EBF telah sesuai dengan persyaratan SNI 1726: 2019 Pasal 7.8.2.1

\section{5) Kontrol Gaya Gempa Dasar}

Dilakukan kontrol terhadap gaya dinamis struktur dengan tujuan agar gaya gempa yang bekerja sesuai dengan yang disyaratkan oleh SNI 1726:2019 pasal 7.8, dengan persamaan gaya geser dasar seismik (V) sesuai persamaan 2.

$V=C_{s} . W$

Perhitungan koefisien respons seismik $\mathrm{C}_{\mathrm{s}}$ adalah sebagai berikut:

$C_{s}=\frac{S_{D S}}{(R / I)}=\frac{0.644783}{(8 / 1)}=0,0806$

Untuk $\mathrm{T} \leq \mathrm{T}_{\mathrm{L}}$, nilai $\mathrm{C}_{\mathrm{s}}$ yang dihitung tidak perlu melebihi :

$C_{S}=\frac{S_{D 1}}{T(R / I)}=\frac{0.564760}{1,291(8 / 1)}=0,0547$

Untuk $\mathrm{T} \geq \mathrm{T}_{\mathrm{L}}$, harus tidak kurang dari :

$C_{S}=0,044 \cdot S_{D S} \cdot I \geq 0,01$

$C_{s}=0,044 \cdot 0,644783 \cdot 1 \geq 0,01$

$C_{s}=0,0284 \geq 0,01$

Maka diambil nilai $C_{s}=0,0547$

Sehingga didapat nilai:

$\mathrm{T} \quad=1,291$ detik

Cs $=0,0547$ (koefisien respons seismik)

$\mathrm{W} \quad=51814,558 \mathrm{kN}$

$V_{\text {statis }} \operatorname{arah} x=C_{S} . W_{t}=2834,256 \mathrm{kN}$

$V_{\text {statis }}$ arah $y=C_{S} . W_{t}=2834,256 \mathrm{kN}$

Berdasarkan SNI 1726:2019, nilai akhir respon dinamis struktur gedung dalam arah yang ditetapkan tidak boleh kurang dari $100 \%$ dari nilai respon statis. Nilai hasil analisis dinamik gaya geser gempa menggunakan SAP 2000 adalah sebagai berikut:

$\mathrm{V}_{\text {dinamis }}$ arah $\mathrm{x} \quad=1707,729 \mathrm{kN}<\mathrm{V}_{\text {statis }}$ arah $\mathrm{x}$

$\mathrm{V}_{\text {dinamis }}$ arah y $\quad=1716,686 \mathrm{kN}<\mathrm{V}_{\text {statis }}$ arah $\mathrm{y}$

Dari hasil analisis di atas maka perlu dilakukan faktor perbesaran gempa sebesar:

Gempa Arah $X=\frac{2834,256}{1707,729}=1,660$

Gempa Arah $\mathrm{Y}=\frac{2834,256}{1716,686}=1,652$

Sehingga nilai $\mathrm{V}_{\text {dinamis }}$ menjadi:

$\mathrm{V}_{\text {dinamis }}$ arah $\mathrm{x} \quad=2834,83 \mathrm{kN}>2834,256 \mathrm{kN}$

$\mathrm{V}_{\text {dinamis }}$ arah $\mathrm{y} \quad=2835,966 \mathrm{kN}>2834,256 \mathrm{kN}$

\section{6) Kontrol Simpangan}

Pemberian batasan pada Simpangan antar lantai dilakukan untuk keperluan kenyamanan penghuni struktur dan mencegah terjadinya kerusakan non struktural. Pada pasal 7.12 SNI 1726:2019, disebutkan bahwa Simpangan antar tingkat desain (4) tidak boleh melebihi Simpangan antar tingkat izin $\left(\Delta_{a}\right)$ :

$\Delta \leq \Delta_{\mathrm{a}}$ 


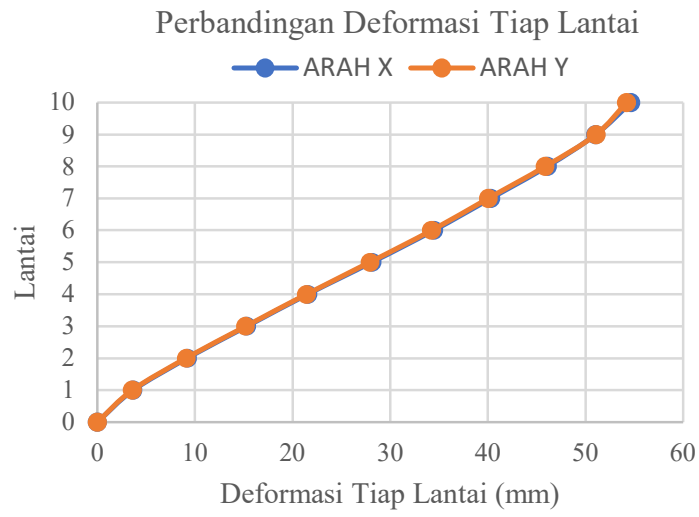

Gambar 8 Perbandingan deformasi antar lantai arah x dan y

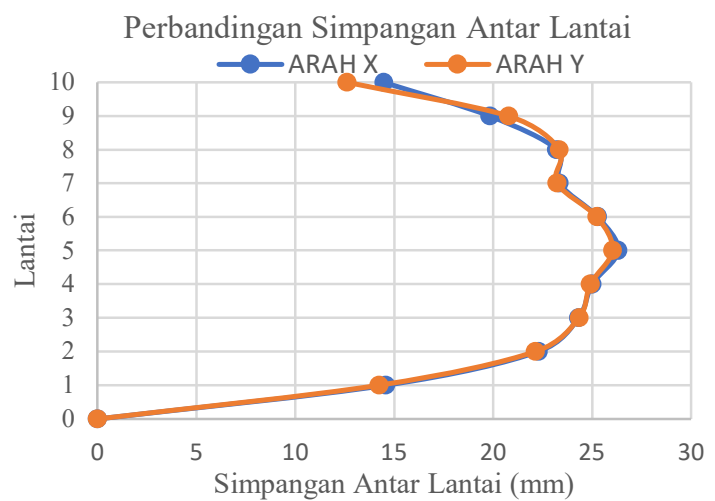

Gambar 9. Perbandingan simpangan antar lantai arah $\mathrm{x}$ dan y

Gambar 8 dan Gambar 9 merupakan perbandingan nilai deformasi dan simpangan antar lantai masing-masing arah sumbu $x$ dan sumbu y. Grafik menunjukkan bahwa nilai simpangan maksimal pada arah $\mathrm{x}=26,32 \mathrm{~mm}$ dan simpangan maksimal arah $y=26,036 \mathrm{~mm}$. Nilai simpangan antar lantai masing-masing arah $\mathrm{x}$ dan arah y dibawah nilai simpangan izin yaitu sebesar $80 \mathrm{~mm}$, sehingga struktur memenuhi syarat dalam kontrol simpangan.

\section{7) Steel Check Design (Kontrol Penampang)}

Kontrol penampang dilakukan dengan menggunakan Steel Check Design pada software SAP2000, dengan tujuan untuk memastikan bahwa profil yang digunakan telah sesuai dengan persyaratan dan kuat dalam menahan beban struktur yang telah diberikan sesuai dengan SNI 1726:2019 dan SNI 1727:2018. Kontrol steel check design dilakukan dengan scale factor beban gempa yang telah dilakukan perbesaran pada kontrol gaya gempa dasar.

\begin{tabular}{|c|c|c|c|c|}
\hline$\frac{\frac{\pi}{2}}{0}$ & 0.16 & ב 7056 & సู̆ & 0.16 \\
\hline క్ & 0.336 & $\begin{array}{lll}0194 \\
0 \\
0\end{array}$ & $\stackrel{\infty}{0}$ & 0.336 \\
\hline కొ & 0.337 & & స్ & 0.337 \\
\hline 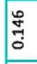 & 0.282 & & ฉ్ & 0.281 \\
\hline 薄 & 0.294 & & స్ & 0.293 \\
\hline$\frac{n}{6}$ & 0.301 & & స్ู & 0.301 \\
\hline సี & 0.298 & & స్ & 0.297 \\
\hline m. & 0.284 & & స్ & 0.284 \\
\hline กี้ & 0.262 & & 悉 & 0.261 \\
\hline 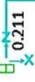 & 0.258 & & f & 0.258 \\
\hline
\end{tabular}

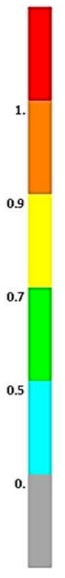

Gambar 10. Hasil steel check design sumbu X-Z

\begin{tabular}{|c|c|c|c|c|}
\hline స્̆ુ & 0.21 & 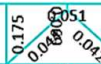 & تี & 0.212 \\
\hline ్ㅕㅇ & 0.317 & 象 & ఫิ๊ & 0.327 \\
\hline $\overrightarrow{\underline{0}}$ & 0.339 & & సุ๊ & 0.351 \\
\hline 궁 & 0.317 & & สู่ & 0.326 \\
\hline ક્ّ & 0.326 & & సู่ & 0.335 \\
\hline స్తి & 0.327 & & ज్సี & 0.336 \\
\hline$\stackrel{m}{0}$ & 0.317 & & స్̃ & 0.326 \\
\hline ले & 0.304 & & 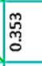 & 0.312 \\
\hline ఫ্ & 0.284 & & F. & 0.292 \\
\hline ন & 0.254 & ๙ & 离 & 0.262 \\
\hline
\end{tabular}

Gambar 11. Hasil steel check design sumbu Y-Z

Gambar 10 dan Gambar 11 merupakan hasil kontrol penampang dengan scale factor perbesaran gaya gempa. Indikator warna menunjukkan bahwa penampang masih dalam kondisi aman, yaitu dengan warna biru dan hijau, serta rasio terbesar pada sumbu $X-Z$ sebesar $0,616<1,0$ dan rasio terbesar pada sumbu Y-Z sebesar 0,608 $<1,0$.

\section{8) Kontrol Analisis Pushover}

Tujuan dari dilakukannya analisis Pushover ini adalah untuk mengetahui perilaku struktur dan keruntuhan atau pelelehan pada elemen-elemen struktur. Pada struktur jenis Eccentrically Braced Frames (EBF) elemen yang diharuskan mengalami pelelehan terlebih dahulu adalah elemen link. 


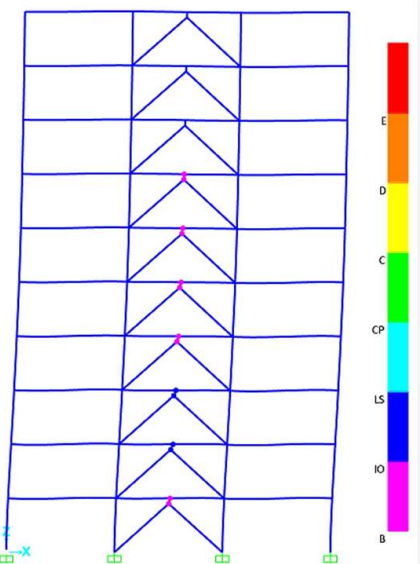

Gambar 12. Analisis Pushover Pelelehan Pertama pada Struktur V-EBF arah $\mathrm{x}$

Hasil analisis Pushover arah x pada struktur Eccentrically Braced Frames (EBF) 10 lantai dengan jenis link vertikal, dari Gambar 12 dapat dilihat bahwa pelelehan pertama terjadi pada elemen link pada lantai 1 hingga lantai 7 step ke 2 , dengan nilai displacement kolom paling bawah pada frame dengan elemen yang mengalami pelelehan yaitu lantai 1 adalah sebesar 14,8 $\mathrm{mm}$ dan nilai displacement kolom paling atas pada frame dengan elemen yang mengalami pelelehan yaitu lantai 7 adalah sebesar $130,7 \mathrm{~mm}$.

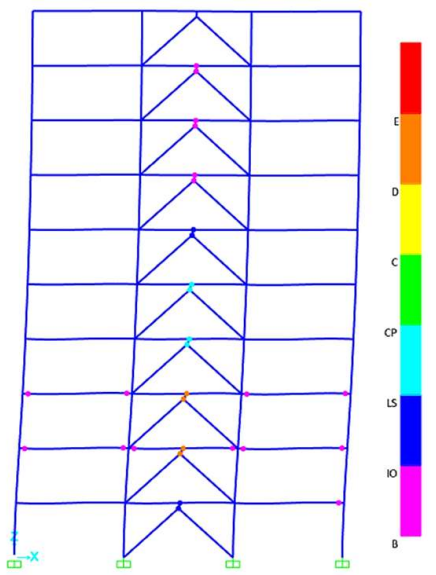

Gambar 13. Analisis Pushover kerusakan terakhir pada struktur EBF arah $\mathrm{x}$

Pelelehan terakhir yaitu pada step ke-9. Seperti yang terlihat pada Gambar 13, terjadi pelelehan pada elemen link lantai 1 hingga lantai 9, serta pelelehan elemen balok pada lantai 1 hingga lantai 3 dengan nilai displacement kolom paling bawah pada frame dengan elemen yang mengalami pelelehan yaitu lantai 1 adalah sebesar $31,1 \mathrm{~mm}$ dan nilai displacement kolom paling atas pada frame dengan elemen yang mengalami pelelehan yaitu lantai 9 adalah sebesar $331,3 \mathrm{~mm}$. Pelelehan yang terjadi pada struktur EBF yang telah dilakukan analisis Pushover telah memenuhi syarat yaitu elemen link mengalami pelelehan terlebih dahulu.

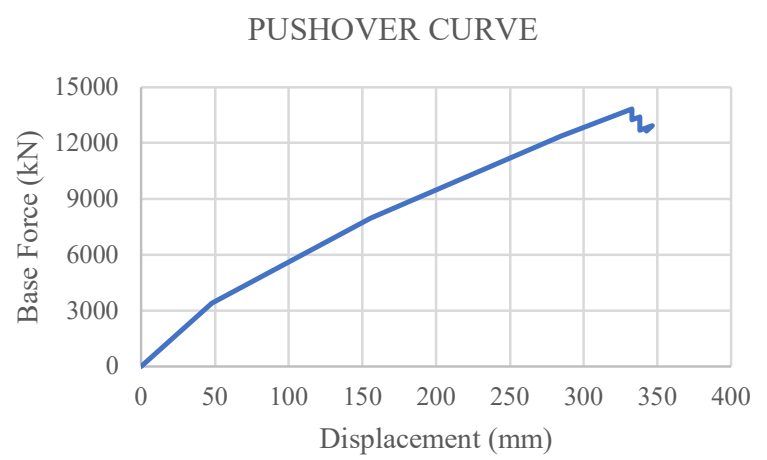

Gambar 14. Grafik hasil analisis Pushover struktur V-EBF

Gambar 14 merupakan grafik hasil analisis Pushover, dapat diketahui bahwa struktur V-EBF mengalami pelelehan pada displacement lantai puncak sebesar 47,972 $\mathrm{mm}$ dengan base force sebesar 3.405,696 kN. Selanjutnya struktur VEBF mencapai nilai ultimate pada displacement sebesar $332,748 \mathrm{~mm}$ dengan base force sebesar 13.832,371 kN. Sehingga dari hasil analisis dapat diketahui daktilitas dari struktur V-EBF adalah sebesar 6,936.

\section{B. Analisis Pemodelan pada Abaqus CAE}

Pemodelan spesimen V-EBF-WF diambil dari dimensi hasil analisis struktur gedung 10 lantai V-EBF pada SAP 2000 dengan mengambil portal lantai 1-4 yang mengalami kegagalan terlebih dahulu pada analisis SAP 2000. Dimensi masing-masing elemen yang digunakan ditunjukkan pada Tabel 8.

Tabel 8 Dimensi Elemen V-EBF-WF pada Pemodelan Abaqus CAE

\begin{tabular}{ll}
\hline Elemen & Dimensi \\
\hline Kolom & KC $800 \times 300 \times 14 \times 26$ \\
Balok & WF $600 \times 200 \times 11 \times 17$ \\
Link & WF $500 \times 200 \times 10 \times 16$ \\
Bracing & WF $600 \times 200 \times 11 \times 17$ \\
\hline
\end{tabular}

1) Hasil Analisis Spesimen V-EBF-WF

Pemodelan spesimen V-EBF-WF, menggunakan EBF dengan link vertikal dengan dimensi yang tercantum pada Tabel 8.

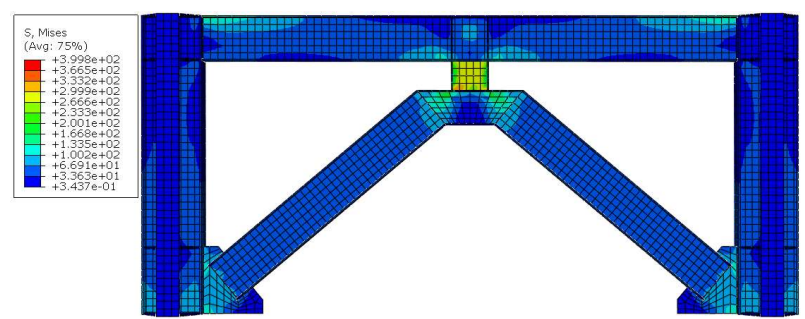

Gambar 15. Tegangan pada Spesimen Frame V-EBF-WF ketika Mencapai Nilai Leleh Pertama $\left(f_{y}\right)$ 


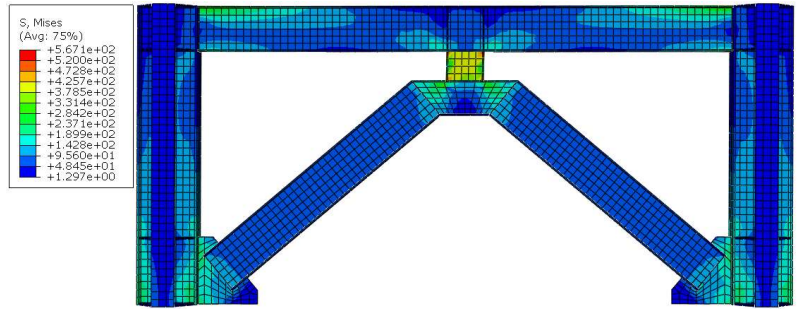

Gambar 16. Tegangan pada Spesimen Frame V-EBF-WF ketika Mencapai Nilai Ultimate $\left(f_{u}\right)$

Spesimen frame V-EBF-WF, elemen link pada frame mencapai tegangan leleh pertama dengan nilai maksimum 399,8 MPa dengan deformasi sebesar 5,252 $\mathrm{mm}$ atau setara dengan 0,00131 rad, dan menghasilkan gaya sebesar $1.266,57 \mathrm{kN}$. Elemen lain seperti balok, kolom, dan bracing belum mengalami pelelehan dengan tegangan maksimum sebesar 233,3 MPa seperti yang terlihat pada Gambar 15. Pada hasil analisis ini elemen link mengalami pelelehan dan mencapai kondisi plastis terlebih dahulu, untuk elemen lain seperti balok, kolom, dan bracing masih dalam kondisi elastis, sesuai dengan persyaratan untuk Eccentrically Braced Frames (EBF). Spesimen V-EBF-WF, elemen link pada frame mencapai tegangan ultimate dengan nilai maksimum 567,1 $\mathrm{MPa}$ dengan deformasi sebesar 14,67 $\mathrm{mm}$ atau setara dengan 0,00367 rad, dan menghasilkan gaya sebesar $2.419,96 \mathrm{kN}$. Elemen lain seperti balok, kolom, dan bracing belum mencapai nilai ultimate dengan tegangan maksimum sebesar 331,4 MPa seperti yang terlihat pada Gambar 16.

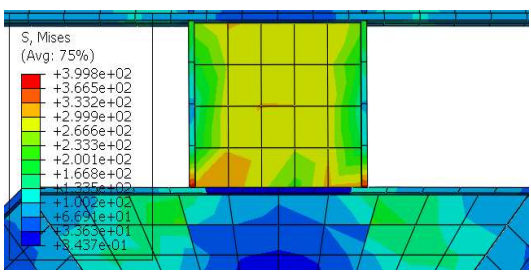

Gambar 17. Kegagalan link WF Saat Mencapai $f_{y}$

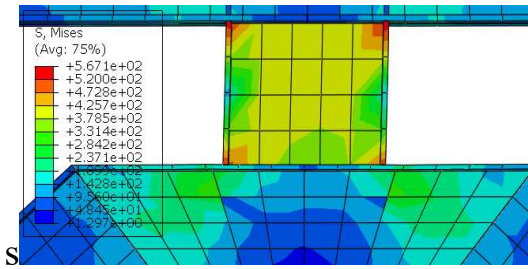

Gambar 18. Kegagalan link WF Saat Mencapai $f_{u}$

Gambar 17. menunjukkan kondisi kegagalan link WF ketika mencapai nilai tegangan leleh $\left(f_{y}\right)$, link WF mengalami pelelehan yang terjadi pada area yang sama yaitu pada web link dan ujung flange link, dan tegangan tertinggi berada pada ujung flange link. Selanjutnya, link WF mencapai nilai ultimate pada area yang sama saat terjadi pelelehan, seperti yang terlihat pada Gambar 18. Kegagalan spesimen V-EBF-WF telah memenuhi konsep struktur Eccentrically Braced Frames (EBF) dengan kegagalan terlebih dahulu terjadi pada link

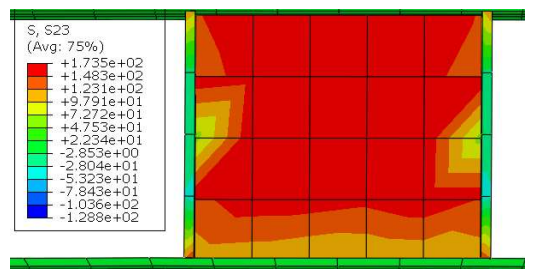

Gambar 19. Kegagalan link WF Ketika Mencapai Pelelehan Geser

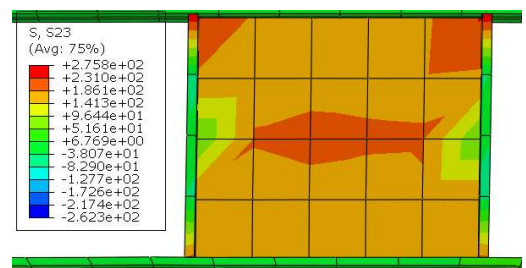

Gambar 20. Kegagalan link WF Ketika Mencapai Ultimate Geser

Gambar 19 menunjukkan kondisi link WF ketika mencapai nilai pelelehan akibat geser, dimana pelelehan link akibat geser terjadi merata pada web link. Kemudian link WF mencapai nilai ultimate geser dengan kegagalan yang terjadi tetap pada web link dan ujung flange link, akan tetapi nilai tegangan tertinggi berada pada tengah web link dan ujung flange link bagian atas, seperti yang ditunjukkan pada Gambar 20. Kegagalan spesimen V-EBF-WF akibat geser telah memenuhi konsep struktur Eccentrically Braced Frames (EBF) dengan kegagalan geser terjadi pada link.

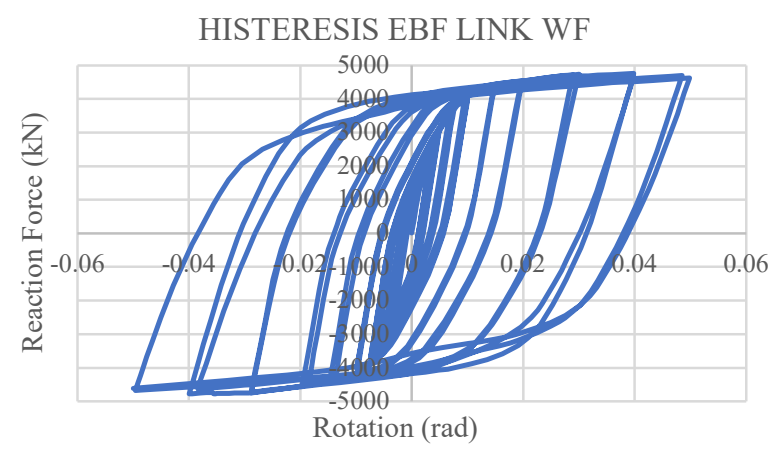

Gambar 21. Kurva Histeresis Spesimen V-EBF-WF

Kurva histeresis pada hasil analisis spesimen V-EBF-WF menunjukkan bahwa gaya maksimum yang diserap oleh spesimen adalah sebesar $4.782,61 \mathrm{kN}$ pada kondisi displacement $159,805 \mathrm{~mm}$ atau setara dengan rotasi sebesar 0,0399 $\mathrm{rad}$ seperti yang terlihat pada Gambar 21. Eccentrically Braced Frame (EBF) dengan link WF ini dapat mendisipasi gaya geser sebesar 2.328,243 kN.m. Sehingga dari hasil analisis 
dapat diketahui daktilitas dari spesimen frame V-EBF-WF adalah sebesar 7,143.

\section{Simpulan}

Berdasarkan hasil analisis dapat disimpulkan sebagai berikut:

1. Pemodelan struktur gedung 10 lantai dengan sistem Eccentrically Braced Frames (EBF) menggunakan 3 tipe dimensi berdasarkan ketinggian lantai, antara lain pada lantai 1-4 menggunakan kolom KC 800x300x14x26, balok dan bracing WF 600x200x11x17, link WF 500x200x 10x16; pada lantai 5-7 menggunakan kolom KC 700x $300 \times 13 \times 24$, balok WF $600 \times 200 \times 11 \times 17$, bracing WF 500x200x10x16, link 450x200x9x14; serta pada lantai 8-

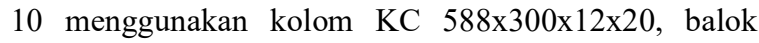
500x200x10x16, bracing 450x200x9x14, dan link 400x $200 \times 8 \times 13$.

2. Hasil analisis linier menggunakan SAP 2000 menunjukkan struktur memenuhi syarat dalam kontrol partisipasi massa, periode, gaya gempa dasar, simpangan, dan steel check design. Hasil analisis non linier Pushover, elemen yang mengalami kegagalan terlebih dahulu adalah elemen link, sehingga struktur sesuai dengan konsep Eccentrically Braced Frames (EBF).

3. Hasil analisis Pushover, dapat diketahui bahwa struktur $\mathrm{V}$-EBF mengalami pelelehan pada displacement lantai puncak sebesar 47,972 mm dengan base force sebesar $3.405,696 \mathrm{kN}$. Selanjutnya struktur V-EBF mencapai nilai ultimate pada displacement sebesar $332,748 \mathrm{~mm}$ dengan base force sebesar 13.832,371 kN. Sehingga dari hasil analisis dapat diketahui daktilitas dari struktur VEBF adalah sebesar 6,936.

4. Pemodelan dan analisis portal 1 lantai dengan Abaqus CAE spesimen V-EBF-WF menggunakan dimensi yang sebelumnya dianalisis pada SAP 2000 yaitu kolom KC 800x300x 14x26, balok dan bracing WF 600x200x11x17, serta link WF 500x200x10x16, menghasilkan performa kapasitas geser maksimum sebesar $4.782,61 \mathrm{kN}$ pada rotasi sebesar 0,0399 rad, mampu mendisipasi energi sebesar 2.328,243 kN.m, serta mempunyai nilai daktilitas sebesar 7,143. Elemen yang mengalami kegagalan terlebih dahulu adalah elemen link, sehingga struktur sesuai dengan konsep Eccentrically Braced Frames (EBF).

\section{Daftar Pustaka}

[1] M. Bruneau, Ductile Design of Steel Structures, New York: Mc Graw Hill, 2011.

[2] B. Suswanto, J. Rafael and W. Sutrisno, Sistem Struktur Eccentrically Braced Frames, Surabaya, 2018.

[3] M. Musmar, "Effect of Link on Eccentrically Braced Frames," Journal of Engineering Sciences, Vols. 40, 1 (1), pp. 35-43, 2012.

[4] N. Mansour, C. Christopolous and R. Tremblay, "Experimental Validation of Replaceable Shear Links for Eccentrically Braced Steel Frames," Journal of Structural Engineering, vol. 137, pp. 1141-1152, 2011.

[5] F. Wang, "Cyclic Behaviour of Y-Shaped Eccentrically Braced Frames Fabricated with HighStrength Steel Composite," Journal of Constructional Steel Research, vol. 120, pp. 176-187, 2016.

[6] M. Shayanfar, A. Rezaeuan and Z. A, "Seismic Performance of Eccentrically Braced Frames with Vertical Link Using PBPD Method," The Structural Design of Tall and Special Buildings, 2012.

[7] B. Suswanto, A. A.R. and E. Wahyuni, "Numerical Behavior Study of Short Link, Intermediate Link, and Long Link in Eccentrically Braced Frames Steel Structure," International Journal of Applied Engineering Research ISSN 0973-4562, vol. 12, pp. 11460-11471, 2017.

[8] AISC341, Seismic Provisions for Structural Steel Buildings, Chicago: AISC, 2016.

[9] SNI1727-2018, Beban Minimum untuk Perencanaan Gedung dan Struktur Lain, Jakarta: Badan Standarisasi Nasional, 2018.

[10] SNI1726-2019, Tata Cara Perencanaan Ketahanan Gempa untuk Struktur Bangunan Gedung dan Non Gedung, Jakarta: Badan Standarisasi Nasional, 2019.

[11] R. Montouri, E. Nastri and V. Pilusi, "Theory of Plastic Mechanism Control for Eccentrically Braced Frames with Inverted Y-Scheme," Journal of Constructional Steel Research 92, pp. 122-135, 2014.

[12] J. Bathe, Finite Element Procedures, United Stated of America: Prentice Hall, 2012.

[13] SNI1729-2015, Spesifikasi untuk Bangunan Gedung Baja Struktural, Jakarta: Badan Standarisasi Nasional, 2015. 